\title{
INSTITUIÇÃO MILITÂNCIA EM ANÁLISE: A (SOBRE)IMPLICAÇÃO DE TRABALHADORES NA REFORMA PSIQUIÁTRICA BRASILEIRA
} EL ANÁLISIS DE LA INSTITUCIÓN MILITANCIA: (SUPER)IMPLICATION DE TRABAJADORES DE LA REFORMA PSIQUIATRICA BRASILEÑA INSTITUTION MILITANCY IN ANALISYS: THE (OVER)IMPLICATION OF WORKERS IN THE BRAZILIAN PSYCHIATRIC REFORM

Michele de Freitas Faria de Vasconcelos e Simone Manieri Paulon

Universidade Federal do Rio Grande do Sul, Porto Alegre/RS, Brasil

\section{RESUMO}

$\mathrm{O}$ artigo parte da problematização do conceito de instituição para propor um debate acerca do processo de institucionalização da Reforma Psiquiátrica em curso no Brasil. Tomando a própria Reforma como instituição, levanta possíveis processos conservadores operando no seio do movimento, o qual resultou na Lei que redireciona o modelo assistencial em saúde mental. Discute, a partir daí, a implicação de trabalhadores da rede de saúde, muitas vezes confundida com a militância que, na sua maioria, os mesmos também exercem no movimento antimanicomial. Finaliza explorando o conceito de sobreimplicação e os possíveis efeitos desse processo nos rumos que a Reforma Psiquiátrica vem tomando no país.

Palavras-chave: política pública; reforma psiquiátrica; desinstitucionalização; militância; sobreimplicação.

\section{RESUMEN}

El artículo comienza con el cuestionamiento del concepto de institución a proponer un debate sobre la institucionalización del proceso de reforma psiquiátrica en marcha en Brasil. Tomando la Reforma misma como institución plantea posibles procesos conservadores que operan dentro del movimiento, lo que resultó en la Ley que vuelve a dirigir el modelo de atención de salud mental. Discute, a partir de ahí, la participación de trabajadores en el sistema de salud, a menudo se confunden con la militancia que, en su mayoría, también tienen el movimiento anti-asilo. Concluye con el análisis del concepto de superimplication y los posibles efectos de este proceso en la dirección que la reforma psiquiátrica está tomando el país.

Palabras clave: política pública; reforma psiquiátrica; desinstitucionalización; militancia; superimplication.

\begin{abstract}
The article problematizes the concept of institution in order to debate the institutionalization process of the Brazilian current Psychiatric Reform. Considering the Reform itself as an institution, it raises possible conservative processes operating in the core of the movement which results in the law that redirects the model of assistance in mental health. From this perspective, the implication of health workers is discussed once it is often confused with the militancy wich they also practice against the asylums. At last, the concept of overimplication is explored to enable the reflection over its effects in the Brazilian Psychiatric Reform.
\end{abstract}

Keywords: public policy; psychiatric reform; deinstitutionalization; militancy; overimplication. 


\section{Notas introdutórias: pistas foucaultianas e nietzscheanas}

"Que mais é preciso para possuir a liberdade do que simplesmente desejá-la?” (Boétie, 1571/2009, p. 16)

Este artigo parte do encontro entre uma provocação teórica e um incômodo pragmático, fazendo convergir reflexões advindas da filosofia da diferença com problematizações experimentadas no corpo a corpo do trabalho em saúde mental. Instigadas pelas argumentações foucaultianas sobre a raridade dos fatos humanos e nietzscheanas sobre a caduquice dos contratos em que se assentam nossa sociedade, vimo-nos convidadas a olhar o campo da Reforma Psiquiátrica à luz dessas afirmações. Isso se desdobra nas seguintes perguntas: Podemos falar de um processo de institucionalização da Reforma Psiquiátrica brasileira? Em que medida o atual cenário das práticas em saúde mental expressam desejos niilistas de conservação? Se o fazem, como fazer frente às forças conservadoras nesse campo? Que ferramentas temos forjado como modos de resistir ao instituído na Reforma Psiquiátrica?

As queixas de inoperância, ingerência, burocracia, negligência, descrédito institucional são muito recorrentes nos serviços de saúde mental, como se os trabalhadores que as enunciam nada tivessem a ver com isso. Falam desses contratos humanos - que são as instituições - como se eles se formassem à revelia de seus desejos, de suas práticas. Reclamando, apenas reclamando, seguem desenvolvendo seus trabalhos, sendo atravessados pela mesma moral, arrimo das instituições das quais tendem a reclamar. "Perdidos" e sem saída aparente para o descrédito institucional, "levando com a barriga" seus trabalhos, seguem o curso apenas fazendo cumprir normas preestabelecidas a favor de um possível préestruturado, institucionalizado. Todavia, não tratemos tal universo como alienado ou inerte; junto dele mesmo, produzem-se resistências-criações, e é para pensar e fortalecer modos de resistir-criar que estamos aqui: re-existir.

Temos defendido a ideia de que a composição imanente entre instituições e subjetividades aproxima, em muito, o dilema institucional do próprio dilema existencial (Paulon, 2006). Numa perspectiva éticopolítica e não tecnocrática, partindo do contexto de nossas atuações acadêmicas, profissionais e clínicopolíticas, nos vemos interpeladas a participar das discussões sobre os rumos da Reforma Psiquiátrica. Nosso objetivo é produzir interferências que primem pela sua desburocratização, pelo seu arejamento, pela produção de práticas que façam frente à institucionalização. Que a luta antimanicomial não perca sua potência de movimento, que ela não se restrinja ao plano das formas!

Nessa direção, cabem as perguntas: O que produz bifurcações? Como operar no plano das forças? Quais as novas arenas de combate? E ainda, o que combater? Como resistir? O que criar? Com que armas/ferramentas? Para isso, buscamos uma escrita-interferência, por meio da qual se possam produzir escapes da linha de composição com a institucionalização da Reforma Psiquiátrica.

Do mesmo modo que falamos àqueles e ao que em nós segue reclamando, "empurrando com a barriga", falamos àqueles que se dizem "militantes" e que não toleram que se problematizem os rumos e os efeitos da cronicidade relacionados às práticas desenvolvidas no bojo da Reforma Psiquiátrica brasileira. Tais militantes, num argumento simplista, alegam que criticar a reforma, neste momento, fortaleceria o movimento contrarreforma e, nele, sobretudo, os lobbys médicopsiquiátricos. Falemos também à militância-em-nós! Compondo os processos de institucionalização da Reforma Psiquiátrica, nós, militantes, de onde quer que hasteemos nossas bandeiras, tendemos a reificar tal processo, olhando-o como "o" novo modelo, barrando seu movimento, sem pensar, ao menos, que poderia ser diferente. Aqui cabe a pergunta de Foucault (1991, p. 83): "como fazer para não vir a ser fascista mesmo quando (sobretudo quando) se crê ser um militante revolucionário? Como desembaraçar nossos discursos e nossos atos, nossos corações e nossos prazeres do fascismo? Como caçar o fascismo que incrustou nosso comportamento?".

A fim de problematizar tal paisagem, nos termos de um esforço de visão para além e para aquém do "lugar ocupado pelo grande aquilo-que-é-óbvio" (Veyne, 2008, p. 255) - e é óbvio militarmos pela Reforma Psiquiátrica, forma institucional pela qual tanto lutamos -, nos parece importante seguir algumas pistas foucaultianas indicadas por Paul Veyne (2008) no texto "Foucault revoluciona a história": Pista 1) Sobre a raridade dos fatos humanos, os quais "não estão instalados na plenitude da razão, há um vazio em torno deles para outros fatos que o nosso saber nem imagina; pois o que é poderia ser diferente" ( $p$. 239); Pista 2) Sobre a necessidade de "desviar os olhos dos objetos naturais para perceber uma certa prática, muito bem datada, que os objetivou" (p. 242). Afinal, para o autor, "outras práticas são sempre possíveis e, nesse sentido, a lista das objetivações permanece aberta, diferentemente dos objetos naturais" ( $p$. 247); Pista 3) Sobre o método foucaultiano, o qual 
consiste em entender que "as coisas não passam de objetivações de práticas determinadas, cujas determinações devem ser expostas à luz, já que a consciência não as concebe" (p. 254).

Tendemos a defender as instituições mais do que a própria vida - o que inclui a defesa de "novas" instituições, a exemplo da instituição Reforma Psiquiátrica -, mesmo quando essas restringem a vida, mesmo quando não nos servem mais os velhos e decadentes valores que outrora nos foram funcionais. Mas de que funcionalidade estamos falando ${ }^{1}$ ? Seria por apego a uma funcionalidade a nossa crença de que as instituições ainda servem? Seria por dívida aos antepassados que fundaram tais perspectivas, disfarçando-se sob o véu da tradição? $\mathrm{Ou}$, ainda pior, seria uma expressão da vontade de nada a nos impedir a ruptura com velhos contratos e invenção de novas perspectivas, novas realidades? Lembremos: perspectivar não deve se confundir com relativizar, o que nos manteria restritos à ideia de uma miríade de olhares sobre uma realidade idêntica a si própria. A produção de realidades demanda, antes, novas perspectivas que requerem a produção de um devir das instituições, das subjetividades (Rodrigues, 2000).

Em outros termos, é preciso deixar de acreditar no que parece óbvio no processo da Reforma Psiquiátrica; ao contrário, parece ser importante historicizá-la. "E, então ... aparece um pequeno objeto de 'época', estranho, raro, exótico, jamais visto" (Veyne, 2008, p. 254). "Não se deve falsear a apreensão do possível sustentando que 'as coisas são o que são', pois, justamente, não há coisas, só existem práticas. E essa é a palavra-chave dessa nova metodologia da história" (p. 264). Historicizar os objetos de que nos ocupamos - no nosso caso a instituição Reforma Psiquiátrica -, significa nos desprendermos da "forma" objeto natural, para fazer aparecer os objetos raros, datados, para que novos caminhos possam ser trilhados, pois outras práticas sempre são possíveis. É nesta tentativa de fazer frente ao instituído e aposta na possibilidade de fazer acontecer o novo, já que a "realidade" é um aberto de possibilidades, que nos colocamos o escopo de refletir sobre instituições, sobre desejos, subjetividades, práticas... Incluindo aí a análise de nossas implicações com o instituído, que, para fins do exercício autoanalítico que aqui se propõe, estamos enfocando como "o militonto ${ }^{2}$ em nós". Essa é a perspectiva do resistir com que este texto propõe-se a interferir.

Não estamos nos referindo a qualquer "novo", como se apenas o fato de mudar, por si só, trouxesse consigo a possibilidade de potencializar o espaço da vida. Estamos nos referindo a um novo ligado ao fluxo das forças do desejo, que explode e transborda. Um novo que insere a diferença na repetição, um bloco de sensações que rompe a lógica do instituído, que diz respeito a:

questões que se preocupam menos com $0<<$ porquê $>>$ das coisas do que com o seu $<<$ como $>>$. Como se introduz o desejo no pensamento, no discurso, na ação? Como o desejo pode e deve despender suas forças na esfera do político e se intensificar no processo de mudança da ordem estabelecida? (Foucault, 1991, p. 82)

Também não nos referimos a coisas que não acontecem, que não estão aqui e que estariam apenas num suposto plano das ideias perfeitas, ranço platônico de ver o mundo. Buscamos a bifurcação, a novidade, a invenção nos espaços mais institucionalizados, entendendo esse movimento de criação, esse plano dos fluxos, das forças, das intensidades como algo que é imanente ao cotidiano dos serviços, ao cotidiano de nossos processos de trabalho, de nossas práticas.

Escrevemos, pois, àqueles e aos fragmentos de cada um de nós que, nos serviços de saúde mental, olham, mas não veem; ouvem, mas não escutam; sentem, mas não se deixam ser afetados. Escrevemos principalmente àqueles e a tudo aquilo que compõe o minoritário. Àqueles e àquilo que, ávidos por novos rumos, não se restrinjam às ressentidas lamúrias da luta pela inclusão dos "desviantes". Ao invés de restringir o movimento ao âmbito jurídico-legal - a interminável batalha pela cidadania -, busquemos a produção de vida, de uma vida que pode mais, mesmo ali onde parece quase nada restar. Rastreemos uma saúde robusta, bem ali onde ela pareça improvável, des-potencializada.

\section{Modulações biopolíticas e a instituição Reforma Psiquiátrica}

Diante da atualização dos modos de poder na forma de uma biopolítica no contemporâneo, de suas modulações, diante das dificuldades de construção, de invenção, de implementação de dispositivos clínico-institucionais que façam deslizar ao invés de pactuarem com relações de controle em vigor, indicase a necessidade de pensar com mais cautela o cenário da Reforma Psiquiátrica e nossas práticas junto a ele.

A significativa conquista que representou a promulgação da Lei 10.216 , ao dispor sobre os direitos das pessoas que têm transtornos mentais serem atendidas prioritariamente em comunidade, só 
foi possível como produto de um amplo movimento de usuários e trabalhadores que passou a se designar por movimento antimanicomial. Manter o caráter de movimento desse processo que resultou na Reforma Psiquiátrica significa reavivar sua potência instituinte. Isso implica não recusar vê-lo enquanto instituição, mas explorar o caráter presente em toda instituição que nunca está inteiramente dada, já que, como tal, convive com forças de conservação e de expansão.

Eis o chamamento: estranhar a "realidade" e os objetos que nela existem ("o" humano, "o" sujeito, "o" método, "a" loucura, "a" saúde mental, "a" reforma psiquiátrica, "os" modos de pensar e praticar saúde-doença-cuidado por ela recomendados). Desse estranhamento, caberia inventar-encarnar novas práticas, outros modos de dizer, viver, conviver, trabalhar, militar, tracejando outros cenários, subjetividades, cuidados em saúde. No caso particular da saúde mental, que essas novas práticas, muitas ainda por vir, possam compor e fortalecer o objetivo de desinstitucionalização da luta antimanicomial. Olhar o que conservamos para saber o que inventamos (Vasconcelos \& Morschel, 2009).

Nesse caminho, os próprios conceitos por nós utilizados só fazem sentido como conceitosferramenta, como ferramentas de trabalho, que nos auxiliem a organizar e executar nossas "tarefas" (Foucault, 2001; Guattari, 2000). Poderes, saberes, subjetividade, institucionalização, implicação, desinstitucionalização, resistência, invenção... $\mathrm{O}$ que, afinal, queremos discutir e mover com tais conceitos? Conexões, diria Deleuze (1972), bifurcações que funcionem a favor do objetivo de tecer uma escrita que aponte caminhos outros que não o da institucionalização da luta e, inclusive, de nossas próprias práticas de escrita.

Entregues a tal processo, nossas seguranças fogem para longe, e somos conduzidas a construir novos itinerários, a atuarmos, nós e os conceitos dos quais nos valemos, como intercessores. Os conceitos não podem pesar na bagagem, ao contrário, devem funcionar como nortes para entrarmos em lugares, muitos por nós ainda não habitados, para experimentarmos, mesmo que sejam territórios ainda por vir. Sigamos, então.

\section{A instituição "Reforma Psiquiátrica" em análise}

O processo de Luta Antimanicomial e a consequente Reforma Psiquiátrica brasileira, ao focarem $o$ processo de desinstitucionalização da loucura, colocam em questão constructos polarizados e naturalizados tais como doença mental/ periculosidade, incapacidade/isenção de direitos, tratamento/confinamento etc. Os Centros de Atenção Psicossocial (CAPS) surgem, assim, como principal instrumento de operacionalização desse processo, objetivando garantir um cuidado de base territorial. São preconizados pelo Ministério da Saúde (MS) para funcionarem como os organizadores das redes municipais de atenção em saúde mental (Ministério da Saúde, 2004a, 2004b).

Contudo, superar o legado asilar, iatrogênico e carcerário, os ranços do antigo modelo, não é um processo simples. Se a Reforma Psiquiátrica permite, de fato, a queda de muros na alçada de visibilidade, o movimento libertário que a gerou levanta, concomitante e inevitavelmente, novos e mais invisíveis muros sustentados pela consistente argamassa de nossos desejos de conservação: "Temos, antes, de procurar saber como este desejo teimoso de servir se foi enraizando a ponto de o amor à liberdade parecer pouco natural" (Boétie, 1571/2009, p. 21).

Já vimos pessoas solicitando que se coloquem cadeados nos portões dos CAPS para impedir os "de dentro" de sair (não só usuários, mas funcionários que querem dali fugir!) e alguns "de fora", outros perigosos, de entrar. Já assistimos usuários que permanecem em acolhimento noturno por muito mais tempo do que o previsto em lei, alguns quase que morando no CAPS. Acompanhamos outros, sem família, principalmente moradores de rua que, por não se encaixarem no perfil de encaminhamento aos residenciais terapêuticos, voltaram a viver nas ruas. Usuários tendem ainda a ficar presos nas malhas da rede de saúde mental, por só ali serem (se sentirem) "incluídos". Ouvimos famílias recusarem-se, não sem justificativas, a participar do processo de cuidado de seus parentes em adoecimento mental por não saberem e/ou não quererem saber como lidar com eles, depois de tantos anos alijadas do cuidado à crise. Vizinhos, nas visitas domiciliares, perguntam: "vocês vieram visitar o doidinho?". Moradores das ruas nos territórios dos CAPS reclamam de sua alocação, para não terem que conviver com loucos e, principalmente, no caso dos CAPS AD, com usuários de álcool e outras drogas. Trabalhadores da saúde, em equipes de Saúde da Família ou quaisquer serviços não especializados, não raramente argumentam contra a Reforma Psiquiátrica, por dizerem-se incapacitados para lidar com a loucura e deslocados de serviços com habilitações específicas para isto.

A lista de "poréns" é longa e permanece aberta. Diante disso, nos parece ser importante olhar, narrar, interferir, fazer ruir outros tantos muros, mais ou 
menos visíveis, feitos dos mesmos tijolos daqueles que cortam toda a cidade em mil pedaços, compondo uma arquitetura "contra" a violência, que faz parte da cena de uma sociedade do confinamento. Sociedade que agora exerce seu controle a céu aberto e espalhase por incontáveis espaços.

Acompanhando a importância histórica do fechamento de tantos manicômios, e sem esquecer de que muitos permanecem abertos, é fundamental fazer transbordar uma discussão que não diz respeito apenas ao modo como entendemos e lidamos com os loucos, mas às formas como entendemos e lidamos conosco e nos relacionamos com a loucura. Tal debate deve ultrapassar os muros da cidade, convocar os habitantes da pólis, não só os consumidores, nem apenas os trabalhadores da saúde e os usuários da rede de saúde mental. Trata-se, pois, de avançar no processo de desinstitucionalização, passando à discussão dos modos como estamos habitando o contemporâneo nos espaços dos serviços.

\section{Da conservação da Reforma à sustentação do movimento}

Se instituições e subjetividades não são essências, naturezas, origens, cabe sempre perguntarmo-nos: como se constituíram de forma tão cristalizada? O que expressam de nossos desejos de conservação? Esses questionamentos que vêm nos acompanhando (Paulon, 2000, 2006) remontam a um tempo bem anterior, no qual o objeto saúde mental sequer existia. Eles parecem refletir preocupações que vão muito além dessa seara, como o Discurso sobre a servidão voluntária de Boétie anunciava nos idos de 1571:

São, pois, os povos que se deixam oprimir, que tudo fazem para serem esmagados, pois deixariam de ser no dia em que deixassem de servir. É o povo que se escraviza, que se decapita, que, podendo escolher entre ser livre e ser escravo se decide pela falta de liberdade e prefere o jugo, é ele que aceita o seu mal, que o procura por todos os meios. $(1571 / 2009$, p.15)

Ao analisar o desejo de servidão, entretanto, Boétie perseguia os desejos de liberdade que, na opinião do autor, compunham um jogo de forças capaz de aventurar-se a reviravoltas que teimem contra o velho hábito de escravidão, afinal, "a liberdade é a única coisa que os homens não desejam; ... [bastando] desejá-la para a possuírem; como se recusassem conquistá-la por ela ser tão simples de obter" (Boétie, 1571/2009, p.18).

A travessia das sociedades disciplinares para as sociedades de controle tem sido alvo de muitas discussões atuais. Nela, tende-se mais "à abertura de um controle contínuo e permanente que ao fechamento descontínuo" nos estabelecimentos disciplinares: escola, fábricas, quartel, conventos, hospitais, hospícios, ou seja, as famosas Instituições Totais com sua arquitetura panóptica (Piovezani-Filho, 2004, p. 145). Entretanto, tal passagem não parece se traduzir em oposição, e sim numa intensificação e generalização da lógica disciplinar. Em outros termos,

a crise contemporânea de tais instituições não significa que os espaços fechados que definiam [seus] espaços limitados deixaram de existir, de maneira que a lógica que funcionava outrora principalmente no interior dos muros institucionais se estende, hoje, a todo o campo social. (Hardt, 2000, p. 369)

Nesse panorama, presenciamos outras formas de confinamento, aliando-se a "antigas", das quais o corpo faz parte, na medida em que entendido como um empreendimento, um bem, algo a se possuir e a sempre melhorar, uma fortaleza sitiada na qual o indivíduo deve se proteger das inseguranças atuais e dos outros indivíduos. Assim, sob o consumo da ilusão autoajuda "só você pode cuidar de si mesmo", nossos corpos, realidades biopolíticas, seguem alvo prioritário da frenética arena disciplina-controle. O que, afinal, haveria então de revolucionário na descentralização do confinamento? No final das contas, com a lógica da descentralização burocráticoadministrativa, como alerta Deleuze (1992, p. 216), “o que está sendo implantado, às cegas, são novos tipos de sanções, de educação, de tratamento. Os hospitais abertos, atendimentos a domicílio", os CAPS? Lembremos da pista dada por Oliveira e Passos (2007, p. 270): algumas práticas gestadas nestes serviços substitutivos de atenção à saúde mental, "em lugar de desinstitucionalizar a loucura, podem criar existências capturadas a "céu aberto"".

Com o objetivo de não perder de vista a análise do funcionamento da biopolítica no contemporâneo e sua relação com a implantação de serviços como CAPS, parece importante pensar os reflexos que têm envolvido a designação, pelo Ministério da Saúde (2004b), do CAPS como principal estratégia do processo de Reforma Psiquiátrica. O que tem acontecido é a consolidação, inegavelmente necessária, de redes de atenção psicossocial fundamentadas nas diretrizes da Política Nacional de Saúde Mental. Mas, quando esse processo começa a se desprender dos movimentos que justificaram sua institucionalidade, sem expressivas participações de movimentos sociais, sem produção de sentido junto aos trabalhadores, aos/às usuários/as e à comunidade, há que se pensar em indicativos de uma institucionalização da Reforma Psiquiátrica. 
Concordamos com Benevides (2003, p.199) nesse ponto, quando afirma a necessidade de uma certa institucionalidade que garanta e legitime as conquistas efetivadas pela política de superação do modelo asilar. Todavia, paradoxalmente, "corre-se o risco de que a necessária institucionalidade dos CAPS se transforme em institucionalização cronificada e cronificadora, reproduzindo o asilamento do qual se quer escapar". Na mesma perspectiva, Oliveira e Passos (2007, p. 271), respaldando-se em Desviat, consideram:

o perigo de uma modulação da relação de tutela operada pelo antigo manicômio para o controle cronificado dos serviços ditos "abertos". Existem sinais visíveis de modulação da série: doença mental - tutela - manicômio para outra que pode constituir outros perigos: doença mental - controle - serviços abertos. ... Por um lado, se há uma intensa luta pelo esvaziamento processual dos manicômios e a conseqüente implantação dos serviços 'abertos', por outro é justamente pela existência de 'muros invisíveis' nesses serviços que pode estar sendo constituída uma nova forma de captura que o contemporâneo nos impõe. O movimento pela autonomia dos usuários dos serviços substitutivos pode coincidir com o momento de sua captura.

Tais efeitos cronicidade parecem indicar a relevância de nos questionarmos acerca dos rumos que o movimento antimanicomial vem tomando, no sentido justamente de reafirmar ou contrariar seu caráter de movimento. Num momento em que alguns "apelidos" como capsilhas, capscômios, ou capscização da rede tendem a falar desses efeitos tomando forma nos (dando forma aos) CAPS, cabe ponderar se, de fato, precisaríamos de um novo Modelo de Assistência em Saúde Mental ou se justamente a institucionalização de um outro Modelo, com "m" maiúsculo, a ser seguido à risca, não estaria também contribuindo para a supracitada, e temida, cronificação.

Ainda conforme Oliveira (2006), o processo de modulação "da doença mental-tutela-manicômio para doença mental-controle-serviços abertos" fornece pistas para se colocarem em análise formas de cronificação, que tendem a atravessar o espaço dos CAPS: (a) cronificação dos usuários, os quais permanecem presos, ainda que de formas diversas, como, por exemplo, na dependência em relação aos serviços. Talvez seja apenas nesses espaços que os usuários se sentem cidadãos, consumidores pelo menos de políticas públicas. Diante disso, vão ali permanecendo por muitos anos, assim como ocorria nos asilos; (b) cronicificação dos profissionais, que tendem a não colocar em análise seus modos de atenção e de gestão, naturalizando-os, novamente; (c) cronificação do cotidiano dos serviços, por meio de sua automação, da promoção de uma "grade" de atividades estereotipada e com frequência inalterada; (d) cronificação dos dispositivos em saúde mental, "produzida pela inexistência ou fragilidade da rede de atenção em saúde, que não amplia nem conecta os diferentes serviços, garantindo uma efetiva abertura dos CAPS que tendem a possuir porta de entrada, mas muitas vezes não possuem porta de saída" (p. 87). No que se refere aos pontos de estrangulação da rede, é importante dizer que a falta de conexão se dá dentro mesmo da própria rede de saúde mental e de saúde de modo mais geral. Essa cronificação é produzida também pela ausência de articulação do sistema de saúde com outras instâncias como educação, justiça, escola, trabalho, assistência social e assim por diante (Vasconcelos \& Mendonça-Filho, 2009).

$\mathrm{O}$ que tais efeitos-cronicidade nos indicariam? Sob o esplendor atmosférico de uma era de direitos, o suposto Estado Democrático de Direito parece funcionar como um estado mínimo social e máximo penal. Num contexto capitalista em que a maioria esmagadora de nós, ditos humanos, vive em condições extremamente miseráveis, ditas não humanas - mas somos nós, humanos, com nossas instituições, que produzimos esse cenário e depois somos nós que propomos humanizá-lo -, enuncia-se um modo de funcionamento estatal que

não mais sustenta a infra-estrutura indispensável ao funcionamento de uma sociedade e adota "uma política de erosão sistemática das instituições públicas". Abandona à lógica do mercado ... e do "cada um por si" segmentos inteiros da população, em especial aqueles que mais precisariam dos seus recursos. (Coimbra ${ }^{3}, 2001$, p. 251)

A partir desse mesmo modo de funcionamento estatal, "tudo" vai para as malhas da justiça, e assim o judiciário vai tomando conta de nossas vidas. De que formas gerir os dispensáveis?

Desse modo, a precariedade das políticas públicas, em particular as de SM, o sucateamento dos serviços e de seus cotidianos, os pontos de estrangulamento da rede de SM, a dificuldade de intersetorialidade, enfim, as supracitadas cronificações não são "algo" que se dá por acaso. Ao contrário, trata-se da instauração proposital de um dado modo de funcionamento de uma política pública que serve para e à pobreza, para e aos "outros", dispensáveis, para aqueles que não fazem parte dos bancos de dados dos cartões de crédito (Baptista, 2001). Ou seja, estamos falando da produtividade de uma política de SM, de uma rede de SM "improdutiva", feita para assim o ser. 


\section{A análise-resistência: por um re-existir da instituição clínica}

Desinstitucionalizar "a" loucura? Lembremos: a pista é nos desviarmos dos objetos naturais e, nesse sentido, não existe loucura através dos tempos, não existe loucura como essência, o ser da loucura, "a" loucura. Se ontologizamos a loucura é apenas para louvá-la, maldizê-la, defini-la "cientificamente" (Veyne, 2008). É isso que intentamos? "O que seria 'materialmente' a loucura fora de uma prática que a faz ser loucura?" (p. 260); “a loucura não existe, só existe sua relação com o resto do mundo" (p. 276); "a loucura não existe como objeto a não ser dentro de e mediante uma prática e, essa prática não é, ela própria, a loucura" (p. 265).

Quando dizemos que a loucura não existe, estamos tentando nos posicionar para além de uma leitura moralizante que afirma ou nega que "os" loucos são vítimas de preconceitos, discriminações, segregações, exclusões, para pensar as práticas muito bem datadas que objetivam, ela e a saúde mental.

Acontece que, em vinte e cinco séculos de história, as sociedades objetivaram de maneiras muito diversas a coisa chamada demência, loucura ou insanidade, para que tenhamos o direito de presumir que nenhum objeto natural se esconde atrás disso e de duvidar do racionalismo da saúde mental. (Veyne, 2008, p. 265)

O objetivo é, então, desnaturalizar os objetos loucura, saúde mental e Reforma Psiquiátrica. Esta última - não podemos esquecer - compõe a cena histórica de um momento de redemocratização do país, pós-ditadura militar, por muitos de nós vivido como uma data perdida na História. A maioria dos que hoje compõem o cenário da saúde mental no país - trabalhadores, acadêmicos, militantes e/ou usuários nem foram presos políticos ou tiveram algum familiar preso e/ou perdido para sempre, nem passaram boa parte da vida num hospital psiquiátrico.

Vivemos sim uma rede de saúde mental "aberta" sob os efeitos de uma luta antimanicomial, fruto do desdobramento da luta política e de práticas de resistência que fazem parte das histórias de muitas pessoas que sofreram na pele os efeitos da ditadura e do manicômio. O convite aqui é para não nos esquecermos da força dessas histórias e, com elas, pensarmos o modelo vigente, de modo a não aceitálo como um dado, algo que sempre foi assim, sempre será e/ou deve manter-se como é. O convite é para que possamos propor desdobramentos-transformações no modelo de saúde mental que temos, de acordo com o que acontece nesses espaços e neste tempo, construir práticas condizentes com nossas histórias e desejos. Podemos desejar outras configurações?

Lembrando que poder é exercício, é combate, há pontos de resistência inscritos no interior dessa rede forjada para ser "improdutiva". Há sempre concorrendo, pari passu aos modos de conservação, os modos criativos de existência. Detenhamo-nos, pois, no ponto de cronificação dos profissionais da rede para um breve exercício de uma possível análise de nossas implicações, o qual possa tensionar pontos de resistência que façam frente ao cerco do instituído. Tensionar para que as forças instituintes ponham-se em movimento e outros modos de funcionamento habitem e subvertam o cotidiano dessa rede. Acreditamos que um modo de resistir dá-se justamente pelo movimento de produzir análises.

Mas não estamos falando de qualquer análise. Em que a produção de análises tem a ver com o objetivo de desinstitucionalizar? Retomemos: até aqui esperamos ter ficado claro que entendemos as formações institucionais como a doença da civilização. Servindo de sustentáculo a uma lógica decadente, são os valores morais de uma determinada cultura que se petrificam em territórios institucionais, o que parece estabelecer uma relação "entre a gênese das instituições e o nosso devir-escravo" (Paulon, 2006, p. 128), homens e mulheres ressentidos, apegados a valores e costumes. Alguém já se perguntou se podemos ser outra coisa que não homens e mulheres? Na lógica do ressentido, as instituições funcionam como ilhas de conservação muito bem fincadas no oceano das forças revoltas dos processos de subjetivação, redes invisíveis de subjetivação moral, que fisgam e matam todos os dias os peixes do acaso, sufocando-os nos ares da atmosfera instituída. E, assim, ao invés de incitarem ações, as instituições prescrevem reações conservadoras face aos acontecimentos, face à novidade.

Anteriormente, alegamos que uma genealogia institucional pode indicar nortes para a análise de nossos desejos de conservação, formas institucionais/ fôrmas desejantes (Paulon, 2006). Pensamos agora que uma genealogia institucional, mais do que isso, pode sinalizar e fortalecer linhas de fuga, movimentos de resistência-criação, de re-existência, de intensidades que trazem consigo a potência de furar o cerco das instituições e de todo tipo de niilismo passivo que as constituem.

Acreditar no impossível, apostar na potência de subversão do novo e na sua possibilidade de trazer arejamento das redes institucionais: criticá-las, desfazê-las, desejá-las outras. Deixar o novo emergir, não acoplá-lo a rostos homogêneos e já dados, trazendo consigo a capacidade de recomposição 
de velhos contratos. Entra em cena a luta por novos modos de subjetividade, pelo devir das instituições. Tal luta apresenta-se como direito à diferença e, mais importante ainda, à variação, à metamorfose, a diferir. Dessa forma, abre-se a possibilidade de nos descolar do homem da ordem, das redes de subjetivação moral, desenformando nossa condição desejante. Colocando nosso desejo em movimento, mesmo que só por alguns instantes descolando-nos dos desejos de conservação, podemos interferir nas instituições.

Nesse mesmo sentido, seguindo os rastros de Foucault, não se pode esquecer que "o poder é em si próprio ativação e desdobramento de uma relação de força", devendo ser analisado em termos de combate, confronto, "uma espécie de guerra silenciosa nas instituições, nas desigualdades econômicas, na linguagem, no corpo social e até mesmo no corpo dos indivíduos" (Foucault, 2001, p. 176). Essa colisão entre forças traz consigo a possibilidade de constituição de novos modos de sensibilidade, de percepção, de relação com o outro e com o mundo, enfim, de novos modos de subjetivação e de novas instituições, situados aquém e além do capitalístico.

Sim, somos modulados pelos sistemas de saber e poder de nossa época; sim, as formações subjetivas se fazem através desses mesmos poderes e saberes - instituídos. Mas não só. Afinal, não há apenas singularidades presas em relações de forças, mas singularidades de resistência capazes de subverter essas relações, há processos de singularização em curso. Homogeneizações e singularizações; linhas de fuga e linhas duras do desejo: paradoxos da vida em instituições. Compondo com os mesmos, podemos reexistir.

Não podemos esquecer o paradoxo a ser por nós habitado, situado logo ali na curva do enfrentamento trágico com nossa condição de seres humanos, seres de instituições, seres impelidos e construídos por um desejo teimoso de servir: no mesmo ponto em que o homem se satisfaz, ele se constrange. Sobre isso, Deleuze nos alerta: "é dentro do homem que devemos libertar a vida, pois o próprio homem é uma forma de aprisioná-las" (Deleuze 1972, p. 132). Foucault (2001, p. 22) segue o mesmo rastro quando aponta que o procedimento genealógico, como análise da proveniência, situa-se no ponto de conexão entre corpo e história, devendo, portanto, elucidar "o corpo inteiramente marcado de história (sobre o corpo se encontra o estigma dos acontecimentos passados) e a história arruinando o corpo".

Nesse sentido, se pensar nos contratos é pensar no que nos impulsiona, mais importante do que perguntar pelo que somos (niilistas passivos, irreversivelmente?) é recusar o que somos (inquietude, superação de si, torções na subjetividade, tarefa desconstrutiva) e, nessa recusa, forjar o que poderíamos vir a ser: transmutar o nada de vontade metafísico em vontade de potência, novos valores para expandir a vida (niilismo ativo), anseio contra a rigidez que nos joga no amorfismo e na apatia.

Diante de tais considerações, ao se pretender fazer uma genealogia institucional, se deve pari passu desenvolveruma genealogia dos modos de subjetivação. Nesse percurso, não se tem como finalidade "buscar a verdade do ser ... mas, sobretudo, diagnosticar técnicas, processos, forças que movem a história, constroem os discursos e constituem os sujeitos" (Sargentini, 2004, p. 94). Ou seja, produzir análises sobre a constituição dos sujeitos na trama histórica da qual participam, bem como sobre os mecanismos e as estratégias empregados pelos diversos equipamentos sociais para instituir e legitimar determinados processos de subjetivação. Respaldando-se numa ética da diferença, do desvio de rotas, da produção desejante, da inventividade, há ainda, e sobretudo, que se procurar pelos movimentos de ruptura, pelas subjetividades dissidentes, pelas singularizações. Aqui o genealogista encontra-se com o cartógrafo. E desse encontro, como já anunciamos anteriormente, emerge o inusitado ali no aparentemente uniformizado: "A vida aparece, então, em sua dimensão criativa para além do estratificado na potencialização de outras estratégias, de novos poderes que 'possam' cada vez mais. ... A vida tem que ser mais do que a está prescrita nos velhos costumes" (Paulon, 2006, p. 131).

Teremos criado dispositivos clínicos para isso? Para que nossas intervenções terapêuticas não permaneçam descoladas de tais discussões é necessário que nossas próprias práticas terapêuticas possam se desarticular do desejo de escravidão para compor com as forças componentes, e não com as formas compostas. Trata-se de abrir a clínica à porosidade, pintando a existência com outras cores que não a da doentia forma homem encarcerado em instituições morais, confinado ao desejo de servir.

A clínica operada nos equipamentos da Reforma Psiquiátrica brasileira não está imune aos territórios institucionais áridos e densos que construímos. A desinstitucionalização da loucura não pode prescindir, por isso, da crítica e desconstrução também de alguns valores que sustentam a instituição da clínica. A articulação entre saberes e fazeres diversos, que reúnam nossas próprias experiências, nossas próprias experimentações e conhecimentos que vimos produzindo para além de rótulos e identidades institucionais de gestores e trabalhadores, especialistas/ terapeutas e usuários, há que ser convocada nessa 
tarefa. Fazer circular saberes transdisciplinares e transversais, caminhar entre noções e práticas advindas da ciência, da filosofia, da religião, da arte, da política, da assistência. Mas, para assim fazê-lo, parece ser necessário, antes, que desejemos inventar outras práticas que não as prescritas em cartilhas de formação corporativa, que não as circunscritas a um modelo de atenção ou às paredes de um serviço.

Aqui, seguimos a pista de Heliana Conde Rodrigues (2009, p. 205), quando ela pergunta se ainda nos lembramos da desinstitucionalização e do que ela implica: transformações radicais. Transformações "nos âmbitos epistemológico, teórico, cultural, jurídico e de ação cotidiana, relativa aos modos de pensar, perceber, sentir e viver a loucura e com a loucura"; transformação de "nossa formação, que passava a ser designada, em seus moldes instituídos, como de-formação". Nessa mesma direção, afirma a autora, desinstitucionalizar demanda a análise de nossa implicação: "a análise de nossos vínculos, constitutivos e mantenedores, com nosso pretenso objeto 'natural', 'racionalizado', 'o patológico' (melhor dizendo, a cisão teórica e cotidiana, entre normal e patológico, ou processo de disciplinamento/ normalização das condutas, [incluindo as nossas])". Ela continua: "Ainda lembramos disso? Ou passamos apenas a registrar/consumir 'novos' serviços?".

\section{A defesa da Reforma Psiquiátrica: sobreimplicação ou neomilitância?}

No percurso por nós apontado, o grande desafio que se coloca aos analistas institucionais, pesquisadores-interventores, pesquisadores-militantes, pesquisadores-trabalhadores dos campos pesquisados parece ser como operar a partir da máquina de Estado sem se deixar seduzir, como tantos companheiros de militância, pela crença no Estado Democrático de Direito. De outro modo, poderíamos dizer que o grande desafio é a "desidealização" do modelo psicossocial e, junto com ele, dos CAPS, bem como a "desidealização" do Estado.

Mas, e quando nossas práticas militantes se colam à imagem da militância identitária? Três eixos, três centralismos de uma militância identitária queremos aqui analisar, pelo que podem ajudar à problematização das novas práticas desinstitucionalizantes no campo da Reforma Psiquiátrica.

Como nos aponta Lourau (1995), a implicação do analista é extremamente importante; portanto, um caminho frutífero, já que implicado sempre se está, pode ser o de colocar tal implicação em análise no processo de pesquisa: análise do lugar que, como especialista, o pesquisador ocupa, busca ocupar e lhe é designado a ocupar. Respaldado numa suposta neutralidade garantida pelo seu olhar de cientista, os regimes de verdade que ele produz costumam ser legitimados.

É então que sua posição pode adquirir uma significação geral, que seu combate local ou específico acarreta efeitos, tem implicações ... Ele funciona ou luta ao nível geral desse regime de verdade, que é tão essencial para as estruturas e para o funcionamento de nossa sociedade. (Foucault, 2001, p. 13)

Com tal afirmação, Foucault nos indica que, como cientistas, como pesquisadores, "são nossas práticas que estão afirmando ou negando certos modelos, produzindo, enfim, os mais diferentes objetos, sujeitos e saberes que estão neste mundo" (Coimbra, 2001, p. 255). Colocar em análise como vêm se dando nossas interferências nos espaços por nós habitados é um modo de resistir, de bifurcar, de colorir e singularizar cenas instituídas, inclusive de pesquisa:

Colocar em análise o lugar que ocupamos, nossas práticas de saber-poder enquanto produtoras de verdades - consideradas absolutas, universais e eternas - seus efeitos, o que elas põem em funcionamento, com o que se agenciam é romper com a lógica racionalista presente no pensamento ocidental e, em especial, na academia. (Coimbra \& Nascimento, 2007, p. 29)

Como apontam Coimbra e Nascimento (2007), para se desenvolver uma "boa" análise de implicação, há que se desenvolver também uma análise de sobreimplicação. Esse conceito "aponta para práticas em que a análise se faz de forma isolada, tomada num único nível, impossibilitando que outras dimensões apareçam", dificultando o processamento de análises de implicação, "visto que todo o campo de análise permanece ocupado por um certo e único objeto" ( $p$. 27). Nessa perspectiva, analisar nossas implicações e sobreimplicações é "uma forma de pensar como vêm se dando nossas diferentes intervenções" (p. 29).

Reiterando nossa posição contrária àquelas que consideram militância e pesquisa práticas incompatíveis, levantamos alguns eixos-centralismos presentes na militância identitária cujas análises permitem abrir passagem para outros modos de pensarfazer militância.

\section{O bandeirismo}

Entra:

em cena um militante/mártir disposto até mesmo a morrer em nome de seus ideais. Para este militante, 
a bandeira que carrega confunde-se com o que ele acredita ser e, muitas vezes não vê que a bandeira que tanto ostenta acabou sendo, aos poucos, "transplantada" para sua córnea. Então, para onde ele mira o olhar, só vê a bandeira e, por isso, deixa de enxergar o que se põe diante de seus olhos. (Oliveira et al., 2009, p. 524)

As bandeiras/identidades se chocam contra as bandeiras de outros militantes (Oliveira et al., 2009). O orgulho Gay, o orgulho Louco, o orgulho da Mulher, tudo com letras maiúsculas, numa tentativa de tornar diferenças emblemáticas identidades governáveis, que se distinguem por diferenças - ou seriam deficiências? - a serem compensadas (Ortega, 2003). Movimentos sociais coadunam com o processo de judicialização da vida cotidiana, restringindo, assim, suas bandeiras à luta por leis que lhe garantam direitos. Para tanto, os membros das identidades ditas dissidentes têm seus rostos homogeneizados e querem esses rostos reconhecidos. Lembremos: toda e qualquer lei traduzse em tutela, controle, prescrições, moral. Luta-se também por punir, criminalizar a sua não aceitação, e a defesa do direito à diferença vê-se, assim, transmutada "em luta contra o outro" (Sawaia, 2004, p. 122): luta do negro contra o branco, luta da mulher contra o homem, luta do homossexual contra o heterossexual. Qual o efeito dessas lutas? Podemos falar, então, de uma prática militante reativa, nos termos nietzscheanos, já que o parâmetro é sempre um outro com que se luta contra, ao invés de se lutar por afirmar a vida.

\section{O ativismo da prática}

Como indicam Coimbra e Nascimento (2007, p. 31), o modo de funcionamento de nossas sociedades neoliberais "tem produzido uma população desassistida que, pela falta de políticas públicas eficazes, ... tem engrossado a procura por profissionais que acreditam poder resolver seus problemas". Essa lógica criadora de demandas perpetua a prática da individualização dos problemas: agora o problema é da falta de competência "dos peritos [incluindo nós, pesquisadores] que trabalham em muitas frentes e em campos diferentes, respondendo às mais variadas questões ao mesmo tempo". Ou seja, o problema da improdutividade das políticas públicas, da produtividade de políticas que foram feitas para assim funcionar, ou seja, o não funcionar é transferido para a falta de competência dos peritos de responderem rapidamente às mais diversas demandas. Essa mesma rapidez, velocidade, aceleração, individualização dominam o mundo atual do "não podemos perder tempo". Assim, nos mais variados espaços sociais, as relações e os encontros se dão de modo apressado, pontual, "superficial, emergencial, levando a situações de pouco acolhimento e solidariedade, nas quais o coletivo vai sendo esvaziado" (p. 32).

Aliadas/os a esse modo de funcionamento, trabalhadoras/es, pesquisadoras/es, militando por suas bandeiras, teorizações, por suas práticas discursivas e não-discursivas, por seus modelos, pleiteando uma hegemonia, adotam a estratégia da acusação para mostrar serviço, o ativismo, a preponderância de sua bandeira, de seu modo de operar como sendo os únicos legítimos a serem sempre copiados e perpetuados, "porque nós, sim, fazemos um bom trabalho". "E aí os encontros são impossibilitados, perdem sua potência transformadora, pois ora, o que vem deles é por nós negado" (Oliveira et al., 2009, p. 524).

\section{O modelismo}

Modelo epistemológico da ciência positivista moderna, modelo biomédico, modelo médicopsiquiátrico-hospitalocêntrico, modelo psicossocial... No que se refere ao modelo assistencial em saúde mental, já nos alertava Pelbárt (s.d.) que, para se superar a herança asilar, iatrogênica e carcerária, os ranços do antigo modelo, não basta desospitalizar, nem basta construir um outro Modelo, nem "mesmo relativizar a noção de loucura compreendendo seus determinantes psicossociais". Há que se enfrentar o que o autor definia por nossos "manicômios mentais em que confinamos a desrazão" (Pelbárt, s.d., p. 51).

Apesar de parecermos estar "abertos", assim como parecem os CAPS, muros invisíveis, jalecos mentais, manicômios daqui, dali, de lá, de qualquer lugar insistem em circunscrever a diferença e o diferente em quadros modelizantes-identitários, afastando-os de "nós", prevenindo possíveis contaminações.

Ampliamos a noção de saúde, ampliamos a clínica, incluímos, pelo menos nos textos da lei e em muitos discursos "engajado-politizados", os loucos na categoria "cidadãos". Num movimento politicamente correto, a reflexão sobre a inclusão/exclusão das pessoas inseridas nos CAPS parece tender a ser realizada como expressão ou negação direta de um modelo unívoco de identidade: afirmando o direito de cidadania aos loucos, esses são apreendidos como Loucos, com L maiúsculo. E, mais, respaldando-se na categoria "loucos", no espaço CAPS, outras diferenças/desigualdades tendem a não ser levadas em consideração ou, pelo menos, não lhes dão a devida atenção: diferenças de classe, de raça/cor, sexuais, de gênero, de religião etc. Ou seja, aquelas pessoas que costumam ser inseridas para o cuidado nos CAPS tendem, ainda, a aparecer, de modo "unilateral e simplista", como "rostos" homogêneos, 
como "aqueles que têm um destino já conhecido e previsível” (Coimbra, 2001, p. 250), participantes de uma ordem homogênea de direitos e de demandas. Sobre isso, ainda afirmam Coimbra e Leitão (2009, pp. 81-82):

a mera afirmação de direitos inalienáveis e de uma essencialidade do que é humano [e do que é loucura], além de estéril e inócua em sua formulação burocrática, produz naturalizações que não reconhecem outros direitos. Comer, morar, trabalhar, ter educação, saúde e transporte dignos são aceitos como necessidades básicas. E as diferentes formas de sensibilidade, de ser e de existir neste mundo, de criar, inventar, mudar? O que temos constatado tem sido, portanto, a afirmação de alguns direitos humanos e, ainda assim, para poucos [identificáveis e identificados].

Se não desconstruirmos a lógica dicotômica e identitária, a qual tende a homogeneizar a diversidade e interceptar devires, aprisionando-os em rótulos, em binarismos hierarquizantes (normal-anormal, homemmulher, heterossexual-homossexual, branco-negro), prosseguiremos apenas camuflando a exclusão e o estigma sobre a retórica da tolerância, sobre a retórica do cuidado em saúde e em saúde mental. Lembremos da linha tênue entre cuidado e tutela. Caso contrário, prosseguiremos circunscrevendo as diferenças a um calhamaço de formas pré-fabricadas de ser, de viver, de conviver.

Pensar tais direitos implica, pois, problematizar o que foi produzido como humano, como essencialmente humano, como essência do humano e, nessa direção, discutir a produção de identidades, entendendo que "a produção de outros 'rostos' de direitos humanos estará, sem dúvida, associada às nossas práticas cotidianas" (Coimbra, 2001, p. 253).

\section{Pela possibilidade de uma neomilitância}

O que nos fascina nos textos de Foucault, de Deleuze, de Guattari, de Nietzsche é o convite/ instigação a pensarmos nosso tempo, o que somos nós neste exato momento e, mais do que isso, colocar em questão isso que somos, estranhar os caminhos que encarnamos, que damos sustentação e que, muitas vezes, naturalizamos. Que forças se instalam no contemporâneo, que forças tomam nosso corpo? Como materializar, como compor com forças de (re)existência que façam dobras nos processos de institucionalização que a todo custo e a toda hora tentam imperar nessa paisagem?

Respaldando-nos, então, numa ética da diferença, do desvio de rotas, da produção desejante, da inventividade, o objetivo é o de procurar pelos movimentos de ruptura, pelas subjetividades, pelos corpos dissidentes-impróprios, pelas singularidades, pelas singularizações. Nesse sentido, preocupamo-nos, sobretudo, em nos constituir, em pensar e experienciar o próprio ato de pesquisar como uma força disruptiva. Mais uma vez, anuncia-se o escopo do nosso trabalho, da nossa militância, das nossas pesquisas, qual seja, o de interferir para:

tentar resistir, tentar furar o cerco da lógica capitalística, do tautismo comunicacional e dos automotismos tecnicistas, criando dispositivos de análise coletiva de implicação e sobreimplicação; produzir espaçostempos em que as lógicas institucionais que nos ordenam possam ser postas em questão [em análise]. (Mendonça-Filho \& Vasconcelos, 2010, p. 147).

São nossas práticas, são as relações dos homens e das mulheres que inventam e sustentam as instituições. Portanto, é por nossas mãos, e não por fatos externos a nós, que podemos mudar tais práticas, relações, instituições e modos de subjetivação. "Nesse terreno de hegemonia do capitalismo tecnofinanceiro e sua tomada de poder" sobre as práticas, os corpos, as subjetividades, "re-existir descrendo, descreditando, extravasando as fronteiras desse possível préestruturado por nós habitado", habitando nossos possíveis e novos lugares (Mendonça-Filho \& Vasconcelos, 2010, p. 148), é desenhar uma militância do entre, preocupada com a criação de espaços coletivos de agenciamento, lembrando que

Agenciar é estar no meio, sobre a linha de encontro entre dois mundos. Agenciar-se com alguém (com alguma coisa) não é substituí-lo, imitá-lo ou identificar-se com ele; é criar algo que não está nem em você nem no outro, mas entre os dois, neste espaço-tempo comum, impessoal e partilhável que todo agenciamento coletivo revela. (Escóssia, 2009, p. 692)

Atuar na contramão da idealização e fixação do humano, dos modelos, das práticas, das instituições e subjetivações, abrir espaço para a interseção, para o encontro e reencontro de "um máximo de conexões" (Escóssia, 2009, p. 692), produzir e fortalecer coletivos, eis a estratégia metódica para guerras com o vazio de sentido e com a naturalização/universalização do "modo-de-ser-indivíduo" (Coimbra \& Nascimento, 2007).

Uma vez que o conceito de instituição não se confunde com o de organização, desinstitucionalizar não pode mais se restringir a simples desmontes físico-estruturais ou meras mudanças nas regras de funcionamento de um estabelecimento. A partir 
da perspectiva da análise institucional, nosso entendimento das instituições se inscreve no jogo de saber-poder do nosso tempo e, nesse sentido, passamos a pensar-fazer a desinstitucionalização como um trabalho micropolítico de desconstrução gradual e permanente das lógicas identitárias e dessingularizantes que ultrapassam em muito os muros das Instituições Totais. Lembremos: estamos tentando fazer frente a um controle extensivo e ilimitado, um controle que faz de muitos de nós dispensáveis, filhos abortados do contemporâneo. Com Nietzsche e o entendimento das instituições como redes invisíveis de subjetivação moral, acrescentamos mais pimenta ao caminho micropolítico proposto, entendendo a empreitada da desinstitucionalização como incessante questionamento de nossos valores. Nesse sentido, não basta os CAPS serem serviços comunitários se não alçarmos o voo de uma transmutação cultural, de uma transvaloração - potencialização dos movimentos que desestabilizem as formas dadas, as quais tendem a aparecer como naturais; é preciso, antes, incansável disposição a inventar, produzir novidades, atualizando e fortalecendo o devir criador de cada um de nós; por último, e não menos importante, é preciso reiterada potencialização e produção de espaços coletivos de análise e de interferência. Essas proposições acabam por fazer de todos e cada um dos trabalhadores de saúde algo de genealogista (Paulon, 2006).

Nesse ponto, podemos bifurcar, nós trabalhadores da saúde mental. Nesse ponto, podemos desejar ser mais do que homens e mulheres filhos da ordem e colados a formas em putrefação. Nesse ponto, podemos desejar mais do que a simples sobrevivência como náufragos adaptados à ilha CAPS, restritos à prática de prescritores, encarregados diretos pelos corpos, obcecados e encegueirados guardiões da moral, na posição de "luta contra a 'doença' ou o 'desvio" (Pelbárt, 2006, p. 12). Como genealogistas, podemos bifurcar. Como genealogistas, nossas análises não se prendem a reconhecer um mundo dado. Analisar, então, passa a existir para produzir mudança de práticas, mudanças nas instituições, torções nas subjetividades.

Colocar as instituições da Reforma Psiquiátrica, da clínica, do especialismo e da militância em análise parece-nos uma boa pista para seguirmos perseguindo caminhos desinstitucionalizantes que permitam a todos nós, clínicos, trabalhadores, militantes e loucos, podermos mais. Sejamos militantes, cujo objetivo é participar da construção de uma ética que nos possibilite transpor o limite de experimentar apenas o condicionado pela sociedade da qual fazemos parte, nos aventurando à criação, "uma produção que possui, em sua emergência, a força de uma conspiração, da invenção de um pouco de possível em um mundo no qual se procura regular/gerenciar a vida na forma de uma mortífera ordem". "Implicados, implicantes" militantes (Rodrigues, 2009, p. 205).

\section{Notas}

Lembremos, com Foucault, de rejeitar todos os ismos: aqui, é preciso dizer não ao funcionalismo. Por exemplo, como nos mostra Foucault (2001), através dos séculos o estabelecimento hospitalar não responde a uma mesma função que tem ser preenchida. Do mesmo modo, as transformações de tal estabelecimento não devem ser explicadas pelos fracassos e sucessos de tal função. Como já apontamos, faz-se necessário partir das práticas sucessivas e heterogêneas, pois, em cada época, o mesmo estabelecimento "servirá a funções diferentes e inversamente; além disso, a função só existe em virtude de uma prática, e não é a prática que responde ao "desafio" da função", "a história é um terreno vago e não um campo de tiro" (Veyne, 2008, p. 269).

2 Devemos esta expressão à colega militante Dra. Carmen Silveira de Oliveira, que nos idos anos 90, tempos de construção ainda incipiente da Reforma Psiquiátrica no $\mathrm{RS}$, designava-nos dessa forma irônica de modo a nos fazer pensar sobre nossas (sobre)implicações.

Em aspas, Coimbra cita Wacquant.

\section{Referências}

Baptista, L. A. (2001). Narrações contemporâneas: vagabundos e turistas nas práticas da saúde mental. In: A. Jacó-Villela, A. Cerezzo, \& H. Rodrigues (Orgs.), Clio-psyché hoje: fazeres e dizeres psi na história do Brasil (pp. 71-84). Rio de Janeiro: Relume Dumará, FAPERJ.

Benevides, R. (2003). Reforma Psiquiátrica Brasileira: resistências e capturas em tempos neoliberais. In $\mathrm{R}$. Benevides, Loucura, Ética e Politica: escritos militantes (pp. 196-206). São Paulo: Casa do Psicólogo.

Boétie, E. (2009). Discurso sobre a servidão voluntária. Brasília: LGE Editora. (Original publicado em 1571)

Coimbra, C. (2001). Operação Rio: o mito das classes perigosas. Rio de Janeiro: Oficina do Autor; Niterói, RJ: Intertexto.

Coimbra, C. \& Leitão, B. S. (2009). Direitos humanos e a construção de uma ética militante. In J. C. Mourão (Org.), Clínica e Política 2: subjetividades, direitos humanos e invenções de práticas clínicas (pp. 315-326). Rio de Janeiro: Abaquar/Grupo tortura Nunca Mais.

Coimbra, C. \& Nascimento, L. (2007). Sobreimplicação: práticas de esvaziamento político? In E. Arantes, M. Nascimento \& T. Fonseca (Orgs.), Práticas PSI inventando a vida (pp. 27-38). Niterói, RJ: EdUFF.

Deleuze, G. (1972). O que é filosofia? São Paulo: Ed. 34.

Deleuze, G. (1992). Conversações, 1972-1990 (Coleção Trans). Rio de Janeiro: Ed. 34.

Escóssia, L. (2009). O coletivo como plano de criação na Saúde Pública. Interface - Comunicação, Saúde e Educação, 13(Supl. 1), 689-694.

Foucault, M. (1991). Anti-Édipo: uma introdução à vida nãofascista. In C. H. Scobar (Org.), Dossier Deleuze (pp. 8184). Rio de Janeiro: Hólon. 
Foucault, M. (2001). Microfisica do poder (16 ed.). Rio de Janeiro: Edições Graal.

Guattari, F. (2000). Caosmose: um novo paradigma estético (3 ed.). São Paulo: Ed. 34.

Hardt, M. (2000). A Sociedade Mundial de Controle. In E. Alliez (Org.), Giles Deleuze: uma vida filosófica (pp. 357372). São Paulo: Ed. 34.

Lourau, R. (1995). Análise institucional. Petrópolis, RJ: Editora Vozes.

Mendonça Filho \& Vasconcelos, M. (2010). Questões de método e pesquisa dos dispositivos institucionais de confinamento do presente. UERJ: Estudos e Pesquisas em Psicologia, ano 10, 1, 134-150.

Ministério da Saúde. (2004a). Legislação em saúde mental: 1990-2004 (5ª ed.). Brasília: Autor.

Ministério da Saúde. Secretaria de Atenção à Saúde. Departamento de Ações Programáticas e Estratégicas. (2004b). Saúde Mental no SUS: os centros de atenção psicossocial. Brasília: Autor.

Oliveira, G. et al. (2009). Novos possíveis para a militância no campo da saúde: a afirmação de desvios nos encontros entre trabalhadores, gestores e usuários do SUS. Interface - Comunicação, Saúde e Educação, 13(Supl. 1), 523-529.

Oliveira, J.A. M. \& Passos, E. H. (2007). Aimplicação de serviços de saúde mental no processo de desinstitucionalização da loucura em Sergipe: um problema clínico-político. Vivência, $32,259-274$.

Ortega, F. (2003). Práticas de ascese corporal e constituição de bioidentidades. Cadernos de Saúde Coletiva, 11(1), 59-77.

Paulon, S. M. (2000). O virtual como dispositivo na clínica institucional. In N. Pellanda \& E. Pellanda (Orgs.), Ciberespaço: Um hipertexto com Pierre Lévy (pp. 207-221). Porto Alegre: Artes e Ofícios.

Paulon, S. M. (2006). A desinstitucionalização como transvaloração. Apontamentos para uma terapêutica ao niilismo. Athenea Digital, 1, 121-136.

Pelbárt, P. (2006). Prefácio. In A. Lancetti, Clínica Peripatética (pp. 11-14). São Paulo: Hucitec.

Pelbárt, P. (s. d.). Manicômio mental - a outra face da clausura. In A. Lancetti (Dir.), Saúde e Loucura (Vol. 2, pp. 132-140). São Paulo: Hucitec.

Piovezani-Filho, C. (2004). Entre vozes, carnes e pedras: a língua, o corpo e a cidade na construção da subjetividade contemporânea. In V. Sargentini \& P. Navarro-Barbosa (Orgs.), Foucault e os domínios da linguagem: discurso, poder, subjetividade (pp. 133-158). São Carlos, SP: Claraluz.

Rodrigues, H. B. C. (2000). Construindo a história do institucionalismo no Brasil: linhas, modelos e ação. In A. Jacó-Vilela et al. (Orgs.), Anais do $1^{\circ}$ Seminário de Historiografia da Psicologia (pp. 49-80). São Paulo: GEHPAI/FAPESP.

Rodrigues, H. B. C. (2009). Formação 'psi': reforma psiquiátrica, atenção psicossocial, desinstitucionalização. In J. C. Mourão (Org.), Clínica e Política 2: subjetividades, direitos humanos e invenções de práticas clínicas (pp. 231252). Rio de Janeiro: Abaquar/ Grupo Tortura Nunca Mais.

Sargentini, V. (2004). A descontinuidade da história: a emergência dos sujeitos no arquivo. In V. Sargentini \& P. Navarro-Barbosa (Orgs.), Foucault e os domínios da linguagem: discurso, poder, subjetividade (pp. 77-96). São Carlos, SP: Claraluz.

Sawaia, B. (2004). O sofrimento ético-político como categoria de análise da dialética exclusão/inclusão. In B. Sawaia, As artimanhas da exclusão: análise psicossocial e ética da desigualdade social (5 $5^{\text {a }}$ ed., pp. 97-118). Petrópolis, RJ: Editora Vozes.

Vasconcelos, M. F. F. \& Mendonça Filho, M. (2009). Por uma genealogia das políticas de saúde mental contemporâneas: da produção de políticas identitárias e de modos variados de confinamento. In M. Mendonça Filho \& M. T. Nobre (Orgs.), Política e afetividade: narrativas e trajetórias de pesquisa (pp. 181-210). Salvador: EDUFBA; São Cristóvão: EDUFS.

Vasconcelos, M. F. F. \& Morschel, A. (2009). O apoio institucional e a produção de redes: do desassossego dos mapas vigentes na Saúde Coletiva. Interface-Comunicação, Saúde e Educação, 13(Supl. 1), 729-738.

Veyne, P. (2008). Como se escreve a história e Foucault revoluciona a história (4a ed.). Brasília: Editora da UNB.

Submissão em: 30/11/2010

Revisão em: 11/05/2012

Aceite em: 11/05/2012

Michele de Freitas Faria de Vasconcelos é Graduada em Psicologia/UFS, mestre em Saúde Coletiva/ISC-UFBa bolsita CNPq e doutora em Educação/UFRGS - bolsista CAPES. Docente do Departamento de Educação/UFS. Pesquisadora do Grupo de Estudos em Educação e Relações de Gênero (GEERGE), vinculado ao PPG em Educação/UFRGS e do Grupo INTERVIRES, vinvulado ao PPG em Psicologia Social e Institucional/UFRGS. Endereço: Campus Universitário Prof. Alberto Carvalho. Av. Vereador Olímpio Grande s/n $\mathrm{n}^{\circ}$. Itabaiana/SE, Brasil. CEP: 49500-000. E-mail: michelevasconcelos@hotmail.com

Simone Mainieri Paulon é Doutora em Psicologia Clínica (PUC-SP). Psicóloga, analista institucional e docente do PPG de Psicologia Social e Institucional, na linha de pesquisa "Clínica, Subjetividade e Política",

e do PPG de Saúde Coletiva - na linha de pesquisa "Saúde, Educação e Sociedade", ambos da UFRGS, onde coordena o grupo INTERVIRES de pesquisa-intervenção em Políticas Públicas, Saúde Mental e Cuidado em Rede. E-mail: simone.paulon@ufrgs.br

\section{Como citar:}

Vasconcelos, M. F. F. \& Paulon, S. M. (2014). Instituição militância em análise: a (sobre)implicação de trabalhadores na Reforma Psiquiátrica brasileira. Psicologia \& Sociedade, 26(n. spe.), 222-234. 